\title{
Lepromatous palate perforation and its surgical repair: a case report
}

\author{
Amardeep Singh, Manjunath K.*, Akash Aradhya S., Manjunatha Rao S. V.
}

Department of Otorhinolaryngology, Basaveshwara Medical College and Hospital, Chitradurga, Karnataka, India

Received: 14 December 2019

Accepted: 30 December 2019

\section{*Correspondence:}

Dr. Manjunath K.,

E-mail: drmanjunathk21@gmail.com

Copyright: ( ) the author(s), publisher and licensee Medip Academy. This is an open-access article distributed under the terms of the Creative Commons Attribution Non-Commercial License, which permits unrestricted non-commercial use, distribution, and reproduction in any medium, provided the original work is properly cited.

\begin{abstract}
Involvement of oral cavity in lepromatous leprosy has been observed in 19-60\% cases and has been described as late manifestation of disease. About $75 \%$ of oral lesions have been observed in the anterior part of hard palate which may result in debilitating complications like perforation of hard palate. We present a case of lepromatous perforation of hard palate that was effectively treated by multidrug therapy for the primary disease. The patient was declared disease free by slit skin smear method and reparative surgery of perforation was done with good results.
\end{abstract}

Keywords: Lepromatous leprosy, Oral lesions, Palatal perforation, Surgical repair

\section{INTRODUCTION}

Leprosy or Hanson's disease is a chronic infectious and contagious disease caused by Mycobacterium leprae. It predominantly affects skin, mucous membrane of the nose and peripheral nerves. Literature on manifestations of leprosy lacks detailed descriptions. Major door of entry of bacillus is upper airway which is also the main route of its elimination. ${ }^{1,2}$ The main reason for preference of this location by M. leprae is its affinity for cooler regions of the body. Involvement of oral cavity is attributed to retropharyngeal secretions in spite of the fact that is relatively resistant to lepromatous lesions because of frequent washing of mouth by salivary secretions. Most frequent site in oral cavity is hard palate followed by soft palate. This can be correlated to the lower mean temperature in the anterior region of palate because of cooling effect of inhaled air by evaporation in this region. ${ }^{3,4}$ Social stigma attached to this disease often leads to delayed medical treatment and more complications. Perforation of palate can be prevented if disease is diagnosed and treated in initial stage. We are reporting a rare case of surgical repair of leprosy related hard palate perforation in a patient who has taken full course of antileprosy drugs and has been declared as germ free.

\section{CASE REPORT}

We present a case of lepromatous perforation of hard palate who had received complete course of treatment for the primary disease. A 30 years old male patient presented with complaints of nasal regurgitation of food and water since one year. Patient had difficulty in mastication and phonation. Past history of patient revealed that patient had skin lesions for previous two years and was diagnosed as a case of type 2 leprosy. Patient had received full course of anti-leprosy therapy for a period of one year which included rifampicin, clofazamine and dapsone. After completion of treatment patient was considered disease free by slit skin smear (SSS) technique. Examination of patient revealed saddle shaped nasal deformity due to erosion of septal cartilage. There was perforation of anterior part of hard palate leading to oro-nasal fistula (Figure 1). Considering clinical condition of patient particularly regurgitation, completion of antileprosy treatment and negativity of disease activity, the patient was taken up for surgical management. The procedure was conducted under 
general anesthesia. Margins of perforation were freshened by removing the marginal tissue which was preserved for histopathological examination for confirmation of disease-free status. Muco-periosteal flap from lateral wall of nasal cavity was elevated and rotated to the floor of the nasal cavity. Palatal flap was raised around fistula and closure of fistula done by putting the rotated flap in position (Figure 2). Histopathological examination of the tissue around perforation revealed nonspecific chronic inflammation. There was no evidence of leprosy. Postoperatively, the patient was observed for a period of three months. Healing of perforation was good with improvement in speech articulation and complete relief from nasal regurgitation (Figure 3).

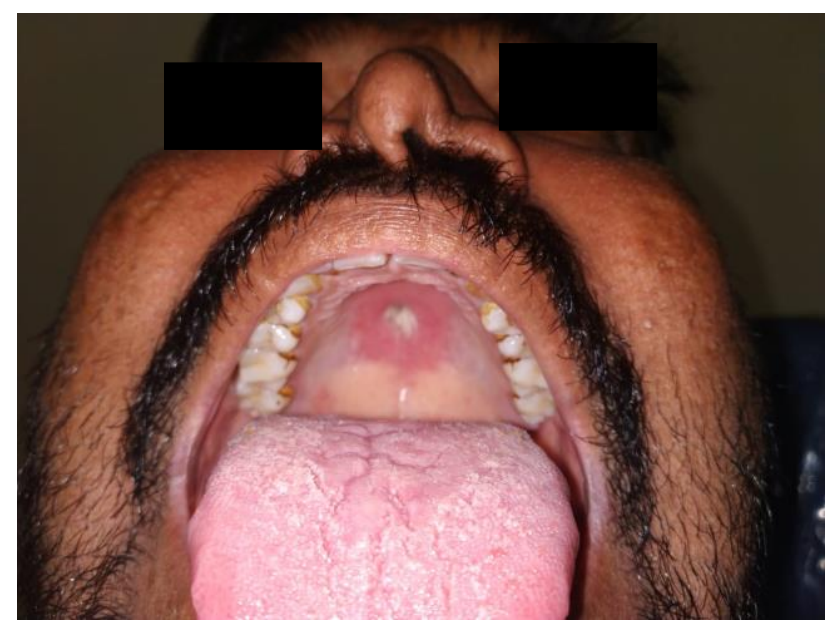

Figure 1: Oronasal fistula over anterior part of hard palate and saddle nose.

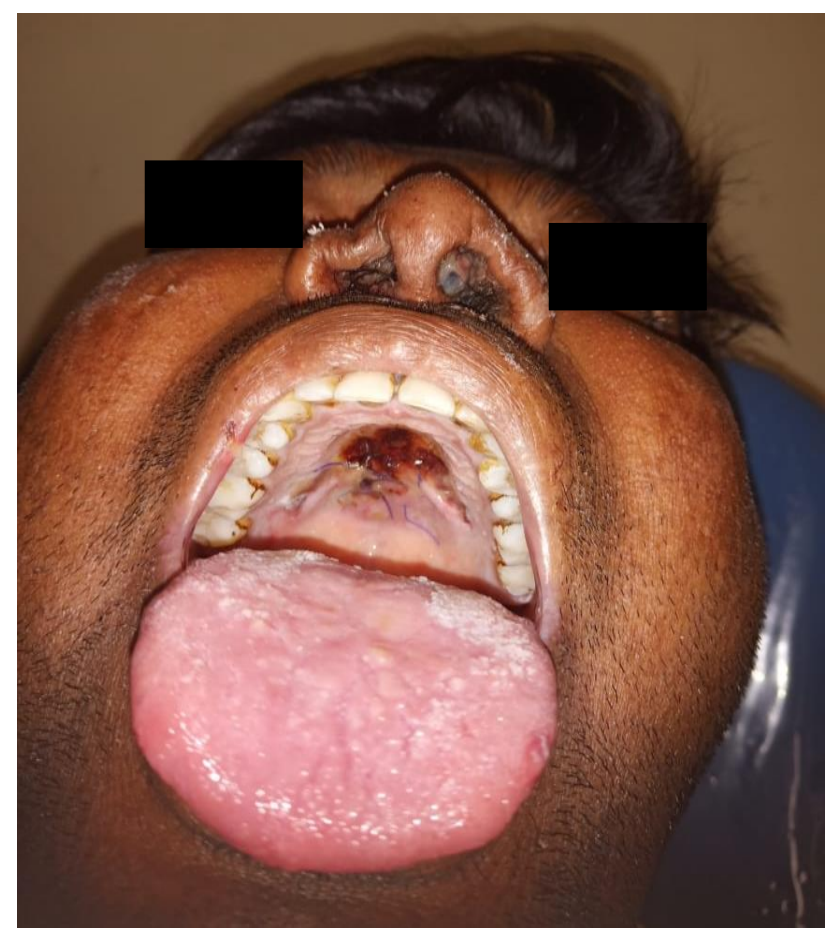

Figure 2: Postoperative photograph showing rotated palatal flaps covering the perforation.

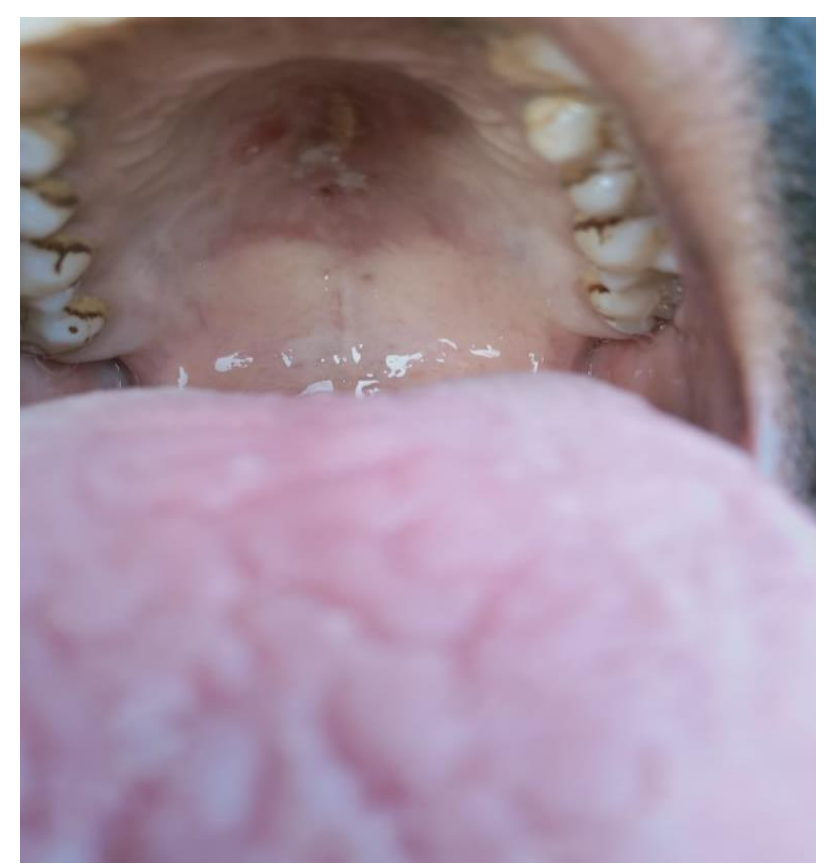

Figure 3: Healed fistula at 3 months follow up.

\section{DISCUSSION}

Oral lesions of leprosy are usually late manifestations of lepromatous leprosy. ${ }^{5}$ Clinical presentation of $M$ leprae infection depends upon the magnitude of immune cellular responses to the bacillus and the innate capacity of patient to fight infection. ${ }^{6}$ Due to improvised methods of leprosy control by introduction of multiple drug therapy, the frequency of oral lesions has been dramatically reduced. Oral cavity leprosy may occur even in the absence of visible lesions in any other part of the body. ${ }^{7}$ In such cases, oral lesions remain clinically doubtful leading to diagnostic problems which call for histopathological examination. ${ }^{1}$ Majority of authors have observed that serious complications of leprosy are seen in palate when compared to other parts of body. ${ }^{2}$ Oral involvement can affect anterior pillars, uvula, buccal mucosa, lips, gums and palate. ${ }^{7}$ About $75 \%$ of oral lepromatous lesions are located in the anterior part of hard palate. Palatal lesions include, inflammation, reddish-yellowish or reddish nodules, ulceration or perforation. ${ }^{1,2,8}$ Due to debilitating complications of oral leprosy, it becomes important that patient should be carefully examined for bacillary aspect of leprosy where there is any suspicion about the etiology of oral lesion. ${ }^{2}$ Oral cavity involvement in leprosy is likely to cause deformities like retraction of soft palate or perforation of hard palate. The resulting functional alterations include disturbances in articulation of words and regurgitation of food. $^{2}$

In the present case, clinical assessment the patient was analyzed on the basis of history and general physical examination for reaching the diagnosis. Once the patient was declared bacillus free by laboratory investigation, the patient was taken up for reparative surgical procedure. 
The patient was followed for three months with good results.

\section{CONCLUSION}

A case of lepromatous perforation of hard palate is presented where the patient has undertaken effective antileprosy therapy for the primary disease. SSS test showed absence of disease activity. Hard palate perforation was repaired by using lateral nasal and rotated palatal mucosal flaps with good anatomical and functional outcome.

Funding: No funding sources

Conflict of interest: None declared

Ethical approval: Not required

\section{REFERENCES}

1. de Abreu MA, Alchome MM, Michalany NS, Weckx LL, Pimentel DR, Hirata $\mathrm{CH}$, et al. Oral mucosa in leprosy: a clinical and histopathological study. Braz J Otorhinolaryngol. 2006;72(3):312-6.

2. Costa A, Nery J, Oliveira M, Cuzzi T, Silva M. Oral lesions in leprosy. Indian $\mathbf{J}$ Dermatol Venereol Leprol. 2003;69:381-5.
3. Scheepers A, Lemmer J, Lownie JF. Oral menifestations of leprosy. Lepr Rev. 1993;64:37-43.

4. Pallagatti S, Sheikh S, Kour A, Aggarwal A, Singh R. Oral cavity and leprosy. Indian Dermatol Online J. 2012;3:101-4.

5. Kishve SP, Giri PA, Shinde KJ. Leprosy of hard palate and the premaxillary gingival: A case report. J Clin Diag Res. 2011;5(6):1286-8.

6. Ghosh S, Gadda RB, Vengal M, Pai KM, Balachandran C, Rao R. Oro-facial aspects of leprosy: Report of two cases with literature review. Med Oral Patol Cir Buccal. 2010;15(3):459-62.

7. Dongre A, Jain S, Gondse S. Palatal perforation: A rare presenting sign of leprosy. J MGIMS. 2010;15:75-6.

8. Bommanavar $\mathrm{S}$, Ingale $\mathrm{Y}$, Ingale $\mathrm{N}$ and Ingale $\mathrm{S}$. Leprosy of hard palate: A rare case report. J Oral Maxillofac Pathol. 2018;22:121-5.

Cite this article as: Singh A, Manjunath K, Akash AS, Manjunatha RSV. Lepromatous palate perforation and its surgical repair: a case report. Int J Otorhinolaryngol Head Neck Surg 2020;6:422-4. 